Kansas State University Libraries

New Prairie Press

\title{
PREDICTING SOIL TEMPERATURES IN HIGH TUNNELS USING A DYNAMIC MODEL BASED ON NEWTONIAN LAW OF COOLING
}

Anil K. Jayaprakash

Kent M. Eskridge

Laurie Hodges

Daryl A. Travnicek

See next page for additional authors

Follow this and additional works at: https://newprairiepress.org/agstatconference

Part of the Agriculture Commons, and the Applied Statistics Commons

\section{(c) (1) $\ominus$}

This work is licensed under a Creative Commons Attribution-Noncommercial-No Derivative Works 4.0 License.

\section{Recommended Citation}

Jayaprakash, Anil K.; Eskridge, Kent M.; Hodges, Laurie; and Travnicek, Daryl A. (2005). "PREDICTING SOIL TEMPERATURES IN HIGH TUNNELS USING A DYNAMIC MODEL BASED ON NEWTONIAN LAW OF COOLING," Conference on Applied Statistics in Agriculture. https://doi.org/10.4148/2475-7772.1134

This is brought to you for free and open access by the Conferences at New Prairie Press. It has been accepted for inclusion in Conference on Applied Statistics in Agriculture by an authorized administrator of New Prairie Press. For more information, please contact cads@k-state.edu. 
Author Information

Anil K. Jayaprakash, Kent M. Eskridge, Laurie Hodges, and Daryl A. Travnicek 


\title{
PREDICTING SOIL TEMPERATURES IN HIGH TUNNELS USING A DYNAMIC MODEL BASED ON NEWTONIAN LAW OF COOLING
}

\author{
Anil K. Jayaprakash ${ }^{1,2}$, Kent M. Eskridge ${ }^{1}$, Laurie Hodges ${ }^{2}$, Daryl A. Travnicek ${ }^{1}$ \\ ( ${ }^{1}$ Dept. of Statistics, UNL, Lincoln, NE 68583. \\ 2 Dept of Agronomy \& Horticulture, UNL, Lincoln, NE 68583.
}

\begin{abstract}
High tunnels are low cost temporary greenhouses that are often used to extend the growing season for high value crops such as tulips, muscari, sweet pea cultivars, and hyacinth beans. Profitability depends on selection and timing of crops to optimize use of these structures. Predicting soil temperatures in high tunnels as a function of outside temperature is a critical factor in crop selection and timing. However, predicting soil temperatures is difficult because air temperatures constantly change from hour to hour and day to day. We develop a model to account for temperature dynamics in high tunnels by modifying the fundamental differential equation in Newtonian law of cooling. We fit the model to data from high tunnels located in two states - Nebraska, Kansas and predict soil temperature as a function of external air temperatures. The model fits reasonably well at all high tunnel stations with most predictions being within $2^{\circ} \mathrm{C}$ of the observed value. We also found that the model could be used to adequately predict soil temperatures at one site based on parameter estimates of another nearby site. Thus we conclude that the model is an adequate tool in making high tunnel placement decisions and is useful for selection and timing of crops within established high tunnels.
\end{abstract}

\section{Introduction}

High tunnels, unlike greenhouses, are temporary structures with manual operation. A simple supporting structure is built high enough to allow a person and equipment to work inside. The structure is covered with a plastic film to retain heat and protect crops from wind and rain. The sidewalls are rolled up manually for ventilation and to regulate internal temperatures. In the simplest form, there is no supplemental heat provided. All heat is provided through solar gain. Extensively used throughout the world, the primary purpose often is for season extension, i.e., earlier maturity in the spring and protection from frost in the fall.

The weather in the Central Great Plains is characterized by extreme variability over relatively short time intervals, as much as 20 degrees $\mathrm{C}$ in a few hours. Growers would benefit from knowing beforehand the likely soil temperatures inside the high tunnel especially under extreme weather conditions.

Most growers will have outside air temperature data but few will have soil temperature data. Predicting high tunnel soil temperature without measuring soil temperature requires a mathematical model that uses air temperature from the grower's site and model parameter estimates from nearby sites. Unlike models for greenhouses where inside and outside solar radiation (El-Shobokshy and Hussein, 1993) or measured solar intensity (Garzoli and Skinner, 1990) is used, solar radiation is not used as input for prediction equations. Thus the model 
developed here is simpler in terms of input variables. This is the first study on the mathematical modeling of air and soil temperatures in high tunnels.

\section{Literature Review}

Greenhouse climate control has seen great improvement in the last 60 years. Throughout the 1940's and 1950's, primitive systems consisted of on-off switches with heating and ventilation determined by separate thermostats. Analog controls gradually developed during the Second World War. It consisted in the use of electrical circuitry inputs from measurements of the environment to calculate the output to a machine that controlled heating and cooling (Carr, 1984). Hammer and Langhans (1978) suggested a model that controlled for 24 environmental parameters.

Use of Lagrange multipliers (Seginer et al., 1986; Gal et al., 1984) and Hamiltonian functions (Challa, 1993; Seginer, 1993; Ponrtyagin et al., 1962) sought to optimize greenhouse operation. The ability to apply mathematical techniques with the help of computers made climate greenhouse modeling a reality in the past decade.

Udink ten Cate $(1983 ; 1987)$, Udink ten Cate and van de Vooren (1984a; b) and Tantau (1980; 1985) developed controllers where staging of several exhaust fans, unit heaters, or ventilators were used. This led to temperature regulation in conventional greenhouses. These regulating systems are often computerized and responsive to existing conditions, rather than predictive. The conventional greenhouse operator seeks to minimize variation in crop growth by precise control of the crop environment. High tunnels, unlike greenhouses, are passive and use a lower level of technology appropriate for low-cost structures. These tunnels are beneficial to growers interested in moderation of climate extremes in protected culture systems rather than precise control of the microclimate. They purely depend on architectural design that can be used to maximize solar gain in the winter (and minimize them in summer) to reduce heating (and cooling) loads.

Most growers have access to ambient air temperature data and forecasts, either from general weather reports or localized agricultural weather reports such as those provided by the High Plains Climate Center (http://hprcc.unl.edu/awdn/home.html). For a grower to predict the soil temperature without actually measuring soil temperature in the high tunnel could enable the selection of crops appropriate for the high tunnel, especially those crops that would take advantage of the season extension capability of the structure.

\section{Objectives}

- Develop a mathematical model to predict soil temperatures in High Tunnels using real data from two states.

- Evaluate the fit and usefulness of the model. 


\section{MATERIALS AND METHODS}

\section{High Tunnels}

The high tunnels used in this study were constructed at Lincoln, Nebraska. Similar tunnels were built by growers in Loth, near Lincoln, Nebraska; and two grower locations - Jozie and Bryzinski near Lawrence, Kansas. The tunnels were modified Stuppy Polar Cub structures (Stuppy Greenhouse Manufacturing, Kansas City, MO.) covered with a single layer of polyethylene greenhouse-grade plastic film (K-50 Clearfilm, Klerk's Plastic Products Manufacturing, Inc., Richburg, S.C.). Modifications consisted of $1.2 \mathrm{~m}$ sidewalls, $1.2 \mathrm{~m}$ bow spacing and $4.8 \mathrm{~cm}$ O.D. 14 gauge column steel bows. Dimensions of Lincoln tunnels were: 14.6 $\mathrm{m} \times 6 \mathrm{~m}$. Lawrence, Kansas had tunnels with dimensions $30 \mathrm{~m} \times 6 \mathrm{~m}$ while Loth had tunnels spanning $60 \mathrm{~m} \times 8 \mathrm{~m}$. Each high tunnel consisted of half of a $14.6 \mathrm{~m} \times 6 \mathrm{~m}$ (or $30 \mathrm{~m} \times 6 \mathrm{~m}, 60 \mathrm{~m}$ $\times 8 \mathrm{~m}$ ) Polar Cub. End walls were constructed of wooden frames covered with the polyethylene film. Each end wall had a sliding door similarly constructed of wood and plastic film. The interior area available for planting and walkways was $14.3 \mathrm{~m} \times 5.7 \mathrm{~m}$ (or $29.7 \mathrm{~m} \times 5.7 \mathrm{~m}, 59.7 \mathrm{~m}$ $\times 7.7 \mathrm{~m})$.

\section{Data}

Data for air and soil temperatures were recorded at these places. The Lincoln high tunnels had Campbell Scientific CR10X microclimate recording systems. The Campbell Scientific thermocouples were calibrated to Polynomial Linearization Error: typically $< \pm 0.5^{\circ} \mathrm{C}\left(-35^{\circ}\right.$ to $\left.+50^{\circ} \mathrm{C}\right),< \pm 0.1^{\circ} \mathrm{C}\left(-24^{\circ}\right.$ to $\left.+45^{\circ} \mathrm{C}\right)$ and Interchangeability Error: typically $< \pm 0.2^{\circ} \mathrm{C}\left(0^{\circ}\right.$ to $\left.+60^{\circ} \mathrm{C}\right)$ increasing to $\pm 0.4^{\circ} \mathrm{C}$ (at $-35^{\circ} \mathrm{C}$ ). Air temperature was measured using temperature probes (Model HMP45C, Campbell Sci., Inc., Logan, UT). Soil temperature was measured using temperature probes (Model 108, Campbell Sci., Inc., Logan, UT). During the measurements, all data were logged every minute, and hourly and daily averages were recorded.

The remaining locations had HOBO data loggers manufactured by Onset. HOBO sensors had an accuracy of $\pm 0.5^{\circ} \mathrm{F}$ at $+70^{\circ} \mathrm{F}$ or $\left( \pm 0.3^{\circ} \mathrm{C}\right.$ at $\left.+20^{\circ} \mathrm{C}\right)$. Both air and soil temperatures for HOBO data loggers were measured using sensors (Model S-THA-MOXX, Onset Computer Corporation, Pocasset, MA). The HOBO data loggers averaged the data which was recorded every 30 minutes.

\section{Position of Sensors}

The Lincoln research station at East Campus, Lincoln NE had 6 high tunnels and the external air temperature was measured at a height of $45 \mathrm{~cm}, 33 \mathrm{~m}$ from the high tunnel. The remaining sites had one internal and one external sensor for measuring soil and air temperatures. The internal soil and air sensors were placed at a depth of $10 \mathrm{~cm}$ and at a height of $45 \mathrm{~cm}$ respectively also at the midpoint of the tunnel sidewall and perpendicular to it. Sensors were placed $150 \mathrm{~cm}$ (five feet) perpendicular to the midpoint. 


\section{Theory}

The model is based on the Newtonian law of cooling which states that the rate of heat loss of an object/body is proportional to the difference in temperatures between the object/body and its surrounding.

In order to apply this principle, let

$T$ be the temperature of the body/object and $T_{0}$ be the temperature of its surrounding.

Newtonian law of cooling can be expressed as

$$
\frac{d T}{d t}=k\left(T_{0}-T\right)
$$

where $k$ is a constant and $\frac{d T}{d t}$ is the rate of change of temperature with respect to time.

The dynamics described by equation [1] is shown in Figure 1.1 We assume that $T_{0}$ is a constant temperature and $T_{0}<T$ and that at $t=0$, the surrounding temperature is decreased to $T_{0}$. Initially $T$ quickly decreases as time $(t)$ progresses i.e. $T$ approaches $T_{0}$ and the rate $\frac{d T}{d t}$ approaches 0 where a steady state is achieved at $T=T_{0}$. Steady state means that the body/object has equilibrated to the surrounding temperature.

The same concept can be applied to a high tunnel. When the sidewalls of a high tunnel are closed, as the outside air temperature changes to some constant level, the soil temperature $(T)$ will change at least to a short-term new average temperature. Similarly when the sidewalls are kept open, the soil temperature $(T)$ would equilibrate to another level. To apply the Newtonian law of cooling to short-term soil temperatures, the model needs to be adjusted to account for the difference between soil temperature and its microclimate.

To do this we define two new variables (see Figure 1.2) as:

$T^{\prime}=T-A_{1}$

where $T^{\prime}$ is the soil temperature computed as the difference between the soil's current temperature $(T)$ and it's long-term average $\left(A_{1}\right)$ and

$T_{0}{ }^{\prime}=T_{0}-A_{0}$

where $T_{0}{ }^{\prime}$ is the outside air temperature computed as the difference between the current air temperature $\left(T_{0}\right)$ and long-term average air temperature $\left(A_{0}\right)$.

After the above two defined variables are substituted for $T$ and $T_{0}$ respectively in eq. [1], $d T / d t=0$ when both $T^{\prime}$ and $T_{0}{ }^{\prime}$ are at their steady state values. If $T_{0}{ }^{\prime}$ decreases below 0 (or $T_{0}<A_{0}$ ) to some constant, $T^{\prime}$ will also decrease but it will not decrease to the same value as $\mathrm{T}_{0}$ ' since the high tunnel steady state soil temperature will differ from the steady state outside air temperature. In other words, the long term average air temperature $A_{0}$ will fluctuate at a different level and correspondingly, soil's long term average $A_{l}$ will depart to a different level. Hence we 
could assume that the new steady state soil temperature is proportional to the outside air temperature say $(1-\alpha) T_{0}{ }^{\prime}$.

Thus $\frac{d T}{d t}=k\left[(1-\alpha) T_{0}^{\prime}-T^{\prime}\right] \quad$ or in terms of $\mathrm{T}$ and $\mathrm{T}_{0}$

$\frac{d T}{d t}=k\left[(1-\alpha)\left(T_{0}-A_{0}\right)-\left(T-A_{1}\right)\right]$

where the new term $T-A_{1}$ is the soil's shifted temperature and $(1-\alpha)\left(T_{0}-A_{0}\right)$ is the outside air temperature shifted to a long-term steady state and re-scaled by $(1-\alpha)$ to account for the adjustment in soil temperature (Fig. 1.2) due to high tunnels.

Solution to eq. [2] assuming $T_{0}$ a constant, results in the equation

$T(t)=(1-\alpha)\left(T_{0}-A_{0}\right)+A_{1}+C e^{-k t}$

where $C=T(0)-T(\infty)$ from equation [3] and $C>0$. i.e. the difference between the soil's initial temperature when $T_{0}=A_{0}$ and its new steady state temperature after $T_{0}$ has decreased below $A_{0}$. The above model is similar to one used in Feng et al (2001) which provided insight into animal temperature dynamics of cattle in controlled temperature chambers, illustrating broad applicability of the model. The parameter $k$ is the soil temperature adjustment factor and is positive. Soils with smaller $k$ values would take longer to adjust to changes in outside air temperature. While soils with a higher $k$ would adjust quickly to changes in air temperature, parameters $\alpha$ and $A_{l}$ can be explained if we assume that as $t \rightarrow \infty$ then eq. [3] becomes

$T(\infty)=(1-\alpha)\left(T_{0}-A_{0}\right)+A_{1}$

since the limit of $e^{-k t}=0$ as $t \rightarrow \infty$. When $T_{0}=A_{0}$, i.e. when the air temperature is at its longterm average, eq. [4] will be $T(\infty)=A_{l}$ which gives the soil's long-term average temperature. The term $(1-\alpha)\left(T_{0}-A_{0}\right)$ indicates a decrease in soil temperature below its long-term average temperature $A_{1}$ when $T_{0}<A_{0} . \quad 1-\alpha$ is the proportion of drop in air temperature below $A_{0}$ that directly translates into the corresponding drop in soil temperature below $A_{1}$. In other words $1-\alpha$ is a scaling factor. Higher $A_{1}$ values indicate that the tunnel's soil will maintain a higher temperature for a given outside air as opposed to a soil with a lower $A_{1}$. Furthermore, tunnel soils with larger $\alpha$ values would lose less heat from a drop in air temperature than soils with a smaller $\alpha$.

\section{Sinusoidal form of high tunnel temperature}

The above model is based on the assumption of a constant air temperature, which is not realistic. Air temperature tends to be cyclic over a 24-hour period, rather than constant. If we assume that $T_{0}(t)$ is a sine function with average $A_{0}$, amplitude $\phi_{0}$ and shift parameter $B_{0}$ (arbitrary starting point on the sine curve), a 24-hour sinusoidal cycle could be written as

$T_{0}(t)=A_{0}+\phi_{0} \sin \left(\eta\left(t-B_{0}\right)\right)$

where $\eta=\frac{2 \pi}{24}$

Substituting $\mathrm{T}_{0}(\mathrm{t})$ from eq. [5] in eq. [2] and solving gives us the equation

$T(t)=(1-\alpha) A_{0}+A_{1}+C e^{-k t}+(1-\alpha) \phi_{0} \cos (\theta) \sin \left(\eta\left(t-B_{0}\right)-\theta\right)$

where $\theta=\tan ^{-1}(\eta / k)$ 
The term $(1-\alpha) \phi_{0} \cos (\theta) \sin \left(\eta\left(t-B_{0}\right)-\theta\right)$ in [6] indicates a cycling in the soil temperature due to the sinusoidal cycling in the air temperature. Note that an additional term $\theta$ is obtained where $\theta$ is the amount of time taken for a change in air temperature to be reflected in soil temperature. In other words $\theta$ is the lag, which is an inverse function of $k\left(\theta=\tan ^{-1}(\eta / k)\right)$. Recall that, the larger the value of $k$, the more rapidly the soil adjusts to the microclimate and smaller the time lag term. As $t$ becomes large, $C e^{-k t}$ becomes small and reduces to a sinusoidal cycling of about $(1-\alpha) T_{0}+A_{1}$ (Fig. 1.3).

Realistically the daily air temperature is not likely to follow a pure sine wave and we thus need a more general temperature function to describe the air temperature, namely

$T_{0}(t)=A_{0}+\sum_{i=1}^{p}\left[\phi_{i} \sin (i \eta t)+\varphi_{\mathrm{i}} \cos (i \eta t)\right]$

where $p$ is the number of Fourier terms in the model (typically $\mathrm{p}=8$ is used).

Now, solution to [2] will be

$T(t)=(1-\alpha) A_{0}+A_{1}+C e^{-k t}+(1-\alpha) \sum_{i=1}^{p} \cos \left(\theta_{i}\right)\left[\phi_{i} \sin \left((i \eta t)-\theta_{i}\right)+\varphi_{\mathrm{i}} \cos \left((i \eta t)-\theta_{i}\right)\right]$

where $\theta$ is related to $i$ as follows :

$\theta_{\mathrm{i}}=\tan ^{-1}(\mathrm{i} \tan (\theta))=\tan ^{-1}(\mathrm{i} n / k)$ and $\theta$ is derived from Eq. [6], i.e. $\theta=\tan ^{-1}(n / k)$.

The parameters from the full model in eq. [6] are useful in characterizing the temperature dynamics in different soils. If we assume that a higher soil temperature is preferred to a lower soil temperature in cold environments, then soils with higher $A_{l}$ values would have higher baseline temperatures (at $T_{0}=0$ ) and thus could lose more heat before freezing.

Higher $\alpha$ values indicate an increased ability to maintain temperature, as $(1-\alpha)$ is the proportion of each air temperature degree that is lost from the soil. Since $k$ is the soil adjustment factor, soils with smaller $k$ values are less responsive to changes in air temperature. Thus the three parameters $A_{l}, \alpha$ and $k$ yield a mathematical description of the soil temperature dynamics.

\section{Fitting the Model}

Data from all locations were used to fit the model separately. A two-stage approach was used to fit the model (eq. [8]). In stage I the raw data from both air and soil temperatures were used to obtain 24 hour running averages, say $\widetilde{T_{0}}(t)$ and $\widetilde{T}(t)$ respectively for each high tunnel. Using eq. [7], the temperature function $\widetilde{T_{0}}(t)$ was estimated to obtain the air temperature parameters $A_{0}, \phi_{i}$ and $\varphi_{\mathrm{i}}$ which resulted in the air temperature predictions $T_{0}(t)_{\text {est }}$. The soil temperature $T(t)$ was then fitted in eq. [8] assuming that the $A_{0}, \phi_{i}$, and $\varphi_{\mathrm{i}}$ estimates were the known parameters resulting in estimated soil temperature $T(t)_{\text {est }}$ conditioned on $t$. In doing so, long-term trends (i.e. day-to-day) for both $T_{0}(t)$ and $T(t)$ were established.

In stage II running averages from stage I $\left(\widetilde{T_{0}}(t)\right.$ and $\left.\widetilde{T(t)}\right)$ were subtracted from $T_{0}(t)$ and $T(t)$ respectively, resulting in a detrending of data. In other words, the second stage is based on 
the residuals of $T_{0}(t)$ and $T(t)$ about the 24-hour running averages. Using eq. [7], the detrended air temperature function $\left(T_{0}(t)-T_{0}(t)\right)$ was estimated to obtain the air temperature parameters $A_{0}{ }^{*}, \phi{ }^{*}$ and $\varphi_{\mathrm{i}}{ }^{*}$ which gave predicted detrended air temperature values $\left(T_{0}(t)-T_{0}(t)\right)_{\text {est. }}$. The detrended soil temperature $(T(t)-T(t))$ was then fitted assuming that the estimates $A_{0}{ }^{*}, \phi_{i}{ }^{*}$ and $\hat{\varphi}_{\mathrm{i}}{ }^{*}{ }^{*}$ were known parameters which resulted in predicted detrended soil temperature values $(T(t)$ $T(t))_{\text {est }}$. All parameters from stage I and II were estimated using non-linear least squares.

Adding back the trends to the residuals gives us our final prediction. The predicted air temperature would be $T_{0}(t)_{\text {est }}=T_{0}(t)_{\text {est }}+\left(T_{0}(t)-T_{0}(t)\right)_{\text {est }}$ and predicted soil temperature would be $T(t)_{e s t}=\widetilde{T}_{(t)} e_{\text {est }}+(T(t)-\widetilde{T(t)})_{\text {est }}$.

If a nearby site, say site $\mathrm{A}$, has both air and soil temperature available, then the estimated $k$ and $\alpha$ from that site (A) could be used in eq. [8] with air temperature data from, say, site $\mathrm{B}$, to predict soil temperature at site B even though soil temperatures at site B are not available. This type of prediction is the focus of objective 2 .

\section{RESULTS AND DISCUSSION}

\section{Objective 1 - Model Explanation}

The model (eq. [8]) was implemented using SAS. Predictions, parameter estimates and goodness of fit statistics $\left(R^{2}\right.$ and Mean Square Prediction Error) were obtained for each location and month. $M S P E=\Sigma(Y-\ddot{Y})^{2} /(\mathrm{n}-1)$ where

(1) Y's were not used to fit model and

(2) Y's are predicted Y's, based on the fitted model

Table 1.1 gives the estimates of the model for Lincoln, Nebraska from September 2002 to March 2004.

Both $k$ and $\alpha$ together reflect the process between external air and internal soil temperatures. Consider the month of December in 2002 as an example (Table 1.1). A $k$ of 0.30 indicated that the rate of change was relatively low while $\alpha$ was 0.42 which was also relatively low, meaning that $1-\alpha=0.58$ or $58 \%$ of an outside temperature degree was reflected in the tunnel soil temperature. The $R^{2}$ was $78 \%$ which indicated that the model fits well for the high tunnel soil temperature. An MSPE of 0.87 indicated that about $95 \%$ of the observed soil temperatures should be within $2 * \sqrt{M S P E}=1.86{ }^{\circ} \mathrm{C}$ of the estimates for the month of December. Similarly we can infer the variation and estimates for other months also from Table 1.1. 
For most months in Lincoln, the model fits well with $R^{2} \geq 75 \%$. Only during winter, especially the months of February 2003, December 2003 and January 2004, did the $R^{2}$ fall below $70 \%$. Also, MSPE was between 1 and 1.5 for most of the months. During the fall months of October 2002, September 2003 and November 2003, the MSPE was between 3 and 3.15. In Table 1.1, the $1 / 2$ confidence interval width was smaller for 2002 than 2003, indicating that the weather in 2002 was less variable (especially during Fall and Winter) as compared to 2003. The $k$ value was high during the summer months (2002) and decreased during the fall (October 2002, November 2002) and winter (December 2002, January 2003 and February 2003). Gradually it picked up during the spring (March, April and May of 2003) and peaked again during summer. Overall, based on $R^{2}$ and MSPE, the model does a good job in estimating high tunnel soil temperature.

\section{Computation of lag times}

Using the model we can also determine inside soil temperature using lag times. From eq. [6] we know that $\theta=\tan ^{-1}(\eta / k)$ is the lag or the amount of time for a change in outside air temperature to be reflected in the tunnel soil temperature. Substituting the December 2002 value of $k=0.12$ from the Lincoln results (Table 1.1) we obtain, $\theta=\tan ^{-1}((2 \pi / 24) / 0.12)=1.14$ radians. Converting radians to hours where 24 hours corresponds to $2 * \pi$ radians, the estimated lag is $\theta=(1.14 * 24) /(2 * \pi)=4.3$ hours. Similarly for other months we can compute the lag time in hours. Substituting the $k$ value of 0.22 for February 2004, we get the lag time as 3 hours. With an estimate of 4.3 hours for January and a rapid outside temperature drop that likely would drop tunnel soil temperatures below a certain threshold, the grower would have approximately 4 hours to make management changes before the full effect would be reflected in the high tunnel soil temperature. Though the soil may not freeze, low soil temperatures can cause damage. To prevent this, management intervention such as installing an artificial heating source, might be used to avoid soil temperature dropping below an acceptable level. With our model, the grower may obtain a reasonable idea of the tunnel soil temperatures. If a grower has an outside air temperature sensor, the grower could use the model to predict soil temperatures based only on outside temperatures.

The model can be most useful in predicting tunnel soil temperatures that could result from a rapid drop in air temperatures. This information could be used to aid growers in making management decisions. The equation for soil temperature can be written as $T(t+\theta)=A_{1}+\left(T_{0}(t)\right.$ $\left.-A_{0}\right) \times(1-\alpha)$. For example, assume that an air temperature drop is predicted to occur at Lincoln, $\mathrm{NE}$ as in Table 1.2. Using the model estimates for March 2003 in Table 1.1, with $k=0.3, \alpha=$ 0.56 and corresponding values of $A_{0}=5.51$ and $A_{1}=4.93$, we can predict what tunnel soil temperatures would result given the situation in Table 1.2. Using the above equation, soil temperature for March 2003 at 2:00 PM in Lincoln would then be estimated as:

$$
\mathrm{T}(\text { time }+ \text { lag })=4.93+(17-5.51) \times(1-0.56)=9.98
$$

where lag or $\theta=\tan ^{-1}(\eta / k)=\tan ^{-1}((2 \pi / 24) / 0.3)=1.523$ radians. Converting radians to hours where 24 hours corresponds to $2 \pi$ radians, lag $=2$ hours $45 \mathrm{~min}$. If the hypothetical air temperature decreases from $17^{\circ} \mathrm{C}$ at $2: 00 \mathrm{PM}$ to $6^{\circ} \mathrm{C}$ at 9:00 $\mathrm{PM}$ then the predicted soil 
temperature drops from $9.98^{\circ} \mathrm{C}$ at $4: 45 \mathrm{PM}$ to $5.1^{\circ} \mathrm{C}$ at $11: 45 \mathrm{PM}$. As midnight approaches, the hypothetical air temperature drops further and remains around $-2^{\circ} \mathrm{C}$. Soil temperature also decreases gradually with outside air temperature but despite the drop in external air temperature, at 2:45 AM, it stabilizes around $2^{\circ} \mathrm{C}$. From Table 1.2, the lag between external air temperature (12 AM) and predicted soil temperature (2:45 AM) is around 2.75 hours. Thus, being able to predict soil temperature for a predicted air temperature drop could be useful for the grower to determine if temporary heating is necessary to maintain soil temperatures.

\section{Evaluating the model - Predicting one site's soil temperature using another site's $k$ and $\alpha$}

To test the application of the model across locations, grower co-operative sites were selected. Here the prediction of Loth from Lincoln and Bryzinski from Jozie is shown. Loth is a grower's location situated 12 miles southwest of Lincoln. As these high tunnels are close to Lincoln high tunnels, we used Lincoln's $k$ and $\alpha$ with Loth's outside air temperature $\left(T_{0}(t)\right)$ to estimate Loth's long term average soil temperature $\left(A_{1}\right)$ and to predict Loth's tunnel soil temperature. As described in theory, we obtained the two stage fit process. In a similar manner we estimated Bryzinski's $A_{1}$ (long term average soil temperature ) using Jozie's $k$ and $\alpha$ and Bryzinski’s $A_{0}$.

Table 1.3 gives a comparison between the $A_{l}$ predictions for Loth's site temperatures using Lincoln's $k$ and $\alpha$ with Loth's air temperature against $A_{l}$ estimated using Loth's air and soil temperature data. Table 1.4 gives a comparison between the $A_{l}$ predictions for Bryzinski's soil temperatures using Jozie's $k$ and $\alpha$ with Bryzinski's air temperature against $A_{l}$ estimated by using Bryzinski's air and soil temperature data. For both Loth and Bryzinski and for both months, the $A_{l}$ values based on the other locations $k$ and $\alpha$ were almost equal to the $A_{l}$ values estimated only with its own data.

The goodness of fit for each location was also evaluated with $R^{2}$ and MSPE. The predictions for a site based on the $k$ and $\alpha$ from another site fit the data better as indicated by higher $R^{2}$ (from Lincoln, Jozie data) and smaller MSPE. The reasons for better prediction for Loth and Bryzinski using Lincoln and Jozie data respectively are likely because, Loth tunnels are $60 \mathrm{~m}$ long with just 1 soil sensor as opposed to Lincoln's tunnel being $15 \mathrm{~m}$ with 4 soil sensors. More heat is lost in a tunnel with long sidewalls as compared with shorter sidewalls and there is less accuracy due to only 1 soil sensor in Loth compared to 4 in Lincoln. In addition though Jozie and Bryzinski have the same length, Jozie has better quality control as its managed by professional growers with many clients as opposed to Bryzinski, which is mainly for in-house cultivation. 


\section{Summary}

These results illustrate the ability of the model to accurately predict soil temperature.

This is useful to a grower in a couple of ways:

1) The usefulness and fit of the model based on data from the Lincoln high tunnel can be seen through the tight prediction of soil temperature based on outside air temperature (Table 1.1). This table shows the following parameter estimates and goodness of fit:

${ }^{1}$ Long term average outside air temperature $\left({ }^{\circ} \mathrm{C}\right)$

${ }^{2}$ Long term average soil temperature inside the high tunnel $\left({ }^{\circ} \mathrm{C}\right)$

3 Rate of change

${ }^{4}$ Scaling factor for adjustment of high tunnel soil temperature based on outside air

${ }^{5}$ Variation of high tunnel soil temperature explained by the model

${ }^{6} \mathrm{MSPE}=$ Prediction error between observed and predicted soil temperatures

${ }^{7} 2 * \mathrm{SQRT}(\mathrm{MSPE})=1 / 2$ width of a $95 \%$ Confidence Interval for the predicted soil temperature

Also, using the hypothetical air temperature (Table 1.2) in the prediction equation (Eq. [9]), would make it easier for a grower to know the soil temperature before an extreme weather condition. This table shows the following:

1 Time of day

${ }^{2}$ External air temperature $\left({ }^{\circ} \mathrm{C}\right)$

3 Time of day + lag

${ }^{4}$ Predicted soil temperature $\left({ }^{\circ} \mathrm{C}\right)$

2) With just a site's air temperature and another site's $k$ and $\alpha$, the grower can predict the soil temperature at the new site. Based on the test location, the model does well in predicting temperatures at one location using the $k$ and $\alpha$ from another location (Tables 1.3 and 1.4).

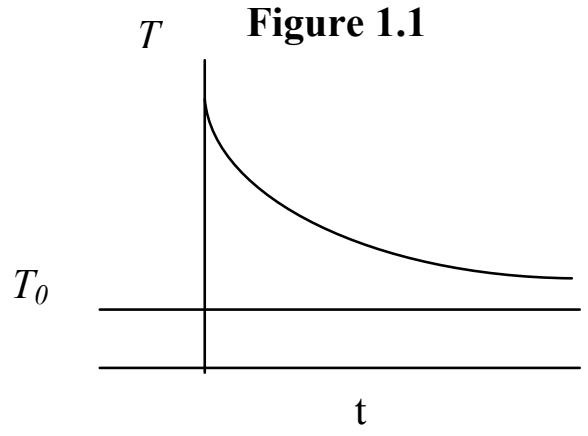


Figure 1.2

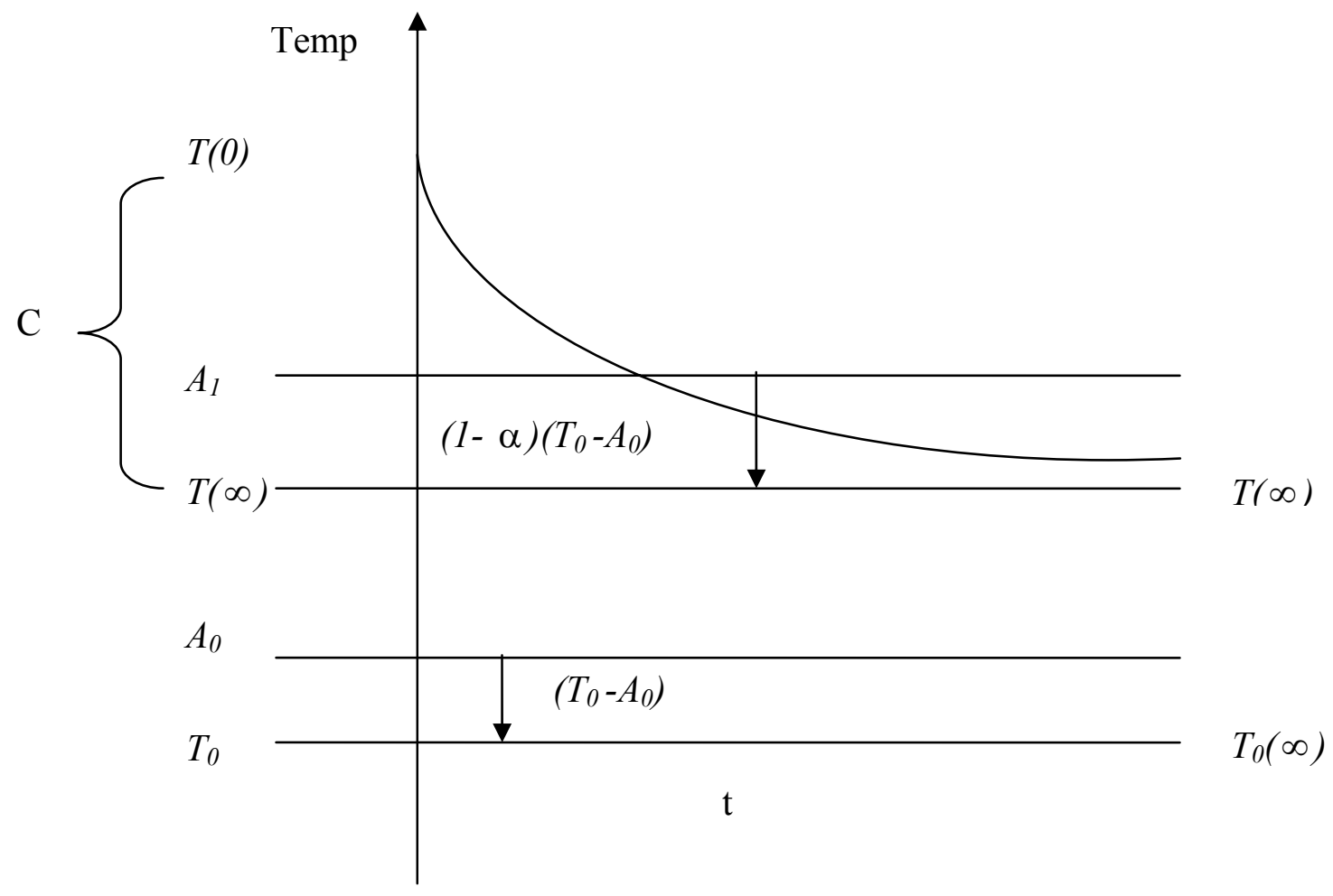

Figure 1.3

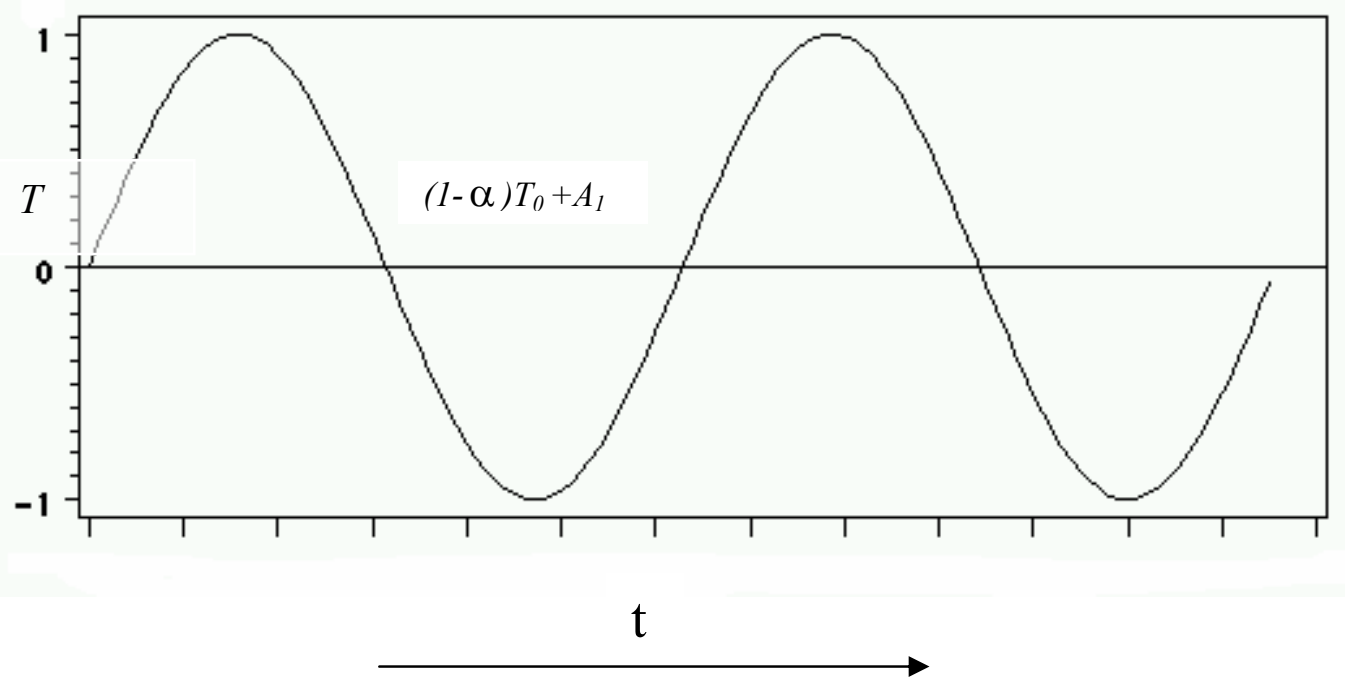


Table 1.1: Parameter estimates and goodness of fit statistics for Lincoln, Nebraska from September 2002 to March 2004

\begin{tabular}{|c|c|c|c|c|c|c|c|}
\hline \multirow[b]{2}{*}{ Months } & \multicolumn{4}{|c|}{ Lincoln Parameter Estimates } & \multicolumn{3}{|c|}{ Goodness of Fit } \\
\hline & $\mathbf{A}_{0}{ }^{1}$ & $\mathbf{A}_{1}^{2}$ & $\mathbf{k}^{3}$ & $\alpha^{4}$ & R Square $^{5}$ & MSPE $^{6}$ & 2*SQRT(MSPE) ${ }^{7}$ \\
\hline Sep-02 & 20.78 & 7.91 & 0.57 & 0.50 & 0.88 & 1.94 & 2.79 \\
\hline Oct-02 & 7.13 & 8.45 & 0.48 & 0.43 & 0.74 & 3.13 & 3.54 \\
\hline Nov-02 & 4.34 & 6.21 & 0.42 & 0.38 & 0.84 & 1.10 & 2.10 \\
\hline Dec-02 & 1.17 & 5.12 & 0.30 & 0.42 & 0.78 & 0.87 & 1.86 \\
\hline Jan-03 & -3.15 & 3.65 & 0.23 & 0.64 & 0.77 & 1.17 & 2.16 \\
\hline Feb-03 & -3.01 & 3.10 & 0.26 & 0.66 & 0.62 & 1.22 & 2.21 \\
\hline Mar-03 & 5.51 & 4.93 & 0.30 & 0.56 & 0.88 & 1.84 & 2.72 \\
\hline Apr-03 & 12.67 & 6.65 & 0.34 & 0.47 & 0.72 & 1.69 & 2.60 \\
\hline May-03 & 14.87 & 10.81 & 0.37 & 0.36 & 0.74 & 1.41 & 2.37 \\
\hline Jun-03 & 21.19 & 14.91 & 0.48 & 0.52 & 0.74 & 2.90 & 3.41 \\
\hline Jul-03 & 27.08 & 13.24 & 0.44 & 0.42 & 0.78 & 1.04 & 2.04 \\
\hline Aug-03 & 26.10 & 18.30 & 0.58 & 0.44 & 0.71 & 1.23 & 2.22 \\
\hline Sep-03 & 17.92 & 8.18 & 0.53 & 0.46 & 0.71 & 3.12 & 3.53 \\
\hline Oct-03 & 13.72 & 8.02 & 0.46 & 0.48 & 0.81 & 2.26 & 3.01 \\
\hline Nov-03 & 4.07 & 5.67 & 0.39 & 0.43 & 0.71 & 3.03 & 3.48 \\
\hline Dec-03 & 0.42 & 3.85 & 0.31 & 0.33 & 0.69 & 1.84 & 2.71 \\
\hline Jan-04 & -4.98 & 3.14 & 0.12 & 0.59 & 0.64 & 2.03 & 2.85 \\
\hline Feb-04 & -5.03 & 3.65 & 0.22 & 0.64 & 0.78 & 2.33 & 3.05 \\
\hline Mar-04 & 5.13 & 3.39 & 0.41 & 0.47 & 0.71 & 1.27 & 2.25 \\
\hline
\end{tabular}

Table 1.2: Hypothetical temperature profile at Lincoln, NE in winter

\begin{tabular}{rccc}
\hline \multicolumn{1}{c}{$\mathbf{t}^{\mathbf{1}}$} & $\mathbf{T}_{\mathbf{0}}(\mathbf{t})^{\mathbf{2}}$ & $\mathbf{( t + \theta )}^{\mathbf{3}}$ & $\mathbf{T}(\mathbf{t}+\theta)^{\mathbf{4}}$ \\
\hline 2:00 PM & 17 & $4: 45 \mathrm{PM}$ & 9.98 \\
6:00 PM & 11 & $8: 45 \mathrm{PM}$ & 7.34 \\
9:00 PM & 6 & $11: 45 \mathrm{PM}$ & 5.1 \\
10:00 PM & 4 & $12: 45 \mathrm{AM}$ & 4.26 \\
11:00 PM & 2 & $1: 45 \mathrm{AM}$ & 3.38 \\
12:00 AM & -2 & $2: 45 \mathrm{AM}$ & 1.62 \\
1:00 AM & -2 & $3: 45 \mathrm{AM}$ & 1.62 \\
2:00 AM & -2 & $4: 45 \mathrm{AM}$ & 1.62 \\
3:00 AM & -2 & $5: 45 \mathrm{AM}$ & 1.62 \\
\hline
\end{tabular}

Table 1.3: Comparison between actual Loth parameter estimates and predicted Loth parameter estimates (obtained using Loth's outside air temperature and Lincoln's $k$ and $\alpha$ ) 


\begin{tabular}{llccccccrr}
\hline & & \multicolumn{4}{c}{ Parameter Estimates } & & \multicolumn{2}{c}{ Goodness of Fit } \\
\cline { 3 - 6 } Location & Soil Temp & Months & $\mathbf{A}_{\mathbf{0}}$ & $\mathbf{A}_{\mathbf{1}}$ & $\mathbf{k}$ & $\mathbf{\alpha}$ & & R Square & MSPE \\
\hline Loth & Actual & May-03 & 13.89 & 11.07 & 0.39 & 0.42 & & 0.74 & 2.74 \\
Loth & Predicted & May-03 & 13.89 & 12.20 & 0.37 & 0.36 & & 0.79 & 2.71 \\
Loth & Actual & Mar-03 & 4.48 & 8.20 & 0.41 & 0.59 & & 0.85 & 2.96 \\
Loth & Predicted & Mar-03 & 4.48 & 9.93 & 0.30 & 0.56 & & 0.88 & 2.19 \\
\hline
\end{tabular}

Table 1.4: Comparison between actual Bryzinski parameter estimates and predicted Bryzinski parameter estimates (obtained using Bryzinski's outside air temperature and Jozie's $k$ and $\alpha$ )

\begin{tabular}{|c|c|c|c|c|c|c|c|c|}
\hline \multirow[b]{2}{*}{ Location } & \multirow[b]{2}{*}{ Soil Temp } & \multicolumn{5}{|c|}{ Parameter Estimates } & \multicolumn{2}{|c|}{ Goodness of Fit } \\
\hline & & Months & $A_{0}$ & $\mathbf{A}_{1}$ & $\mathbf{k}$ & $\alpha$ & R Square & MSPE \\
\hline Bryzinsk & Actual & Jan-03 & -2.21 & 4.00 & 0.35 & 0.62 & 0.76 & 2.10 \\
\hline Bryzinsk & Predicted & Jan-03 & -2.21 & 4.83 & 0.37 & 0.55 & 0.78 & 1.70 \\
\hline Bryzinsk & Actual & Feb-03 & -0.95 & 4.92 & 0.40 & 0.63 & 0.70 & 0.96 \\
\hline Bryzinsk & Predicted & Feb-03 & -0.95 & 5.23 & 0.36 & 0.57 & 0.73 & 0.95 \\
\hline
\end{tabular}

\section{REFERENCES}

Carr, J. J. 1984. Interfacing Your Microcomputer to Virtually Anything. TAB Books, Inc., Blue Ridge Summit, PA. 325 pp.

Challa, H, 1993. Optimal diurnal climate control in greenhouses as related to greenhouse management and crop requirements. In the Computerized Greenhouse. Y. Hashimoto et al., eds. Academic Press, San Diego.

El-Shobokshy, M.S. and F.M. Hussein, 1993. "Particulate effect on the performance of greenhouses", Renewable Energy, 3, 655-660.

Gal, S. A. Angel and I. Seginer. 1984. “Optimal control of greenhouse climate: Methodology”. European J. Operational Res. 17:45-56.

Garzoli, K.V. and Skinner, R.W. 1990. Design and economic evaluation of a solar greenhouse, CISRO Centre for Irrigation Research. Griffith, N.S.W., Australia, Personal Communication. Hammer, P.A. and R. W. Langhans. 1978. "Modeling of plant growth in horticulture". 
HortScience. 13:456-458.

Hanan, J.J. 1970. “Observations on radiation in greenhouses”. CO Flower Growers Assoc. Res. Bull. 239:1-4.

Ponrtyagin, L.S. et al. 1962. The Mathematical Theory of Optimal Processes. John Wiley Interscience, New York 360 pp.

Seginer, I. Et al. 1986. “Optimal $\mathrm{CO}_{2}$ enrichment strategy for greenhouses: A simulation study”. J. Agric. Eng. Res. 34:285-304.

Seginer, I. 1993. “Crop models in greenhouse climate control”. Acta Hort. 328:79-97.

Feng, S., Parkhurst, A.M., Eskridge, K.M., Travnicek, D.A., Spiers, D., Hahn, G.L. and Mader, T. 2002, "Assessing refinements in modeling sinusoidal conditions used to drive cattle body temperatures”. Applied Statistics in Agriculture 2001, P299-312, G.A. Milliken Ed. Kansas State Univ., Manhattan, KS.

Tantau, H.J. 1980. “Climate control algorithms”. Acta Hort. 106: 49-54.

Tantau, H.J. 1985. "The ITG digital greenhouse climate control system for energy saving”. Unpubl. Manuscript, Inst. For Hort. Eng., Hannover. 7 pp.

Udink ten Cate. A.J. 1983. "Modeling and (adaptive) control of greenhouse climates". Ph.D. Dissertation. Landbw. Wageningen. 159 pp.

Udink ten Cate. A.J. 1987. "Analysis and synthesis of greenhouse climate controllers. In computer applications in Agricultural Environments". J.A Clark et al., eds. Butterworths, London, Chap.1, pp1-20.

Udink ten Cate. A.J. and J. van de Vooren. 1984a. "New models for greenhouse climate control". Acta Hort. 148: 277-285.

Udink ten Cate. A.J. and J. van de Vooren. 1984b. "Modelling of greenhouse temperature using time-series analysis techniques”. $9^{\text {th }}$ IFAC World Congress, Budapest. 1: 272-276. 